ESJ Social Sciences

\title{
Ragging: A Harmless Tradition or Menace? Perspective of Newly Admitted Medical Students of Karachi, Pakistan
}

\author{
Shafaq Taseen \\ Karachi Medical \& Dental College, Pakistan \\ Syed Musab Arshad Shah \\ Karachi Medical \& Dental College, Pakistan \\ Munib Abbas \\ Karachi Medical \& Dental College, Pakistan \\ Falak Munaf Aziz Gafooli \\ Karachi Medical \& Dental College, Pakistan \\ Kashmala Hamid \\ Karachi Medical \& Dental College, Pakistan \\ Anzila Rabbani \\ Karachi Medical \& Dental College, Pakistan
}

Doi:10.19044/esj.2021.v17n8p123

Submitted: 11 November 2020

Accepted: 15 March 2021

Published: 31March 2021
Copyright 2021 Author(s)

Under Creative Commons BY-NC-ND

4.0OPEN ACCESS

Cite As:

Taseen,S., Shah, AMS., Abbas, M., Gafooli, AMF., Hamid, K., andRabbani,A. (2021). Ragging: A Harmless Tradition or Menace? Perspective of Newly Admitted Medical Students of Karachi, Pakistan. European Scientific Journal, ESJ, 17(8), 123. https://doi.org/10.19044/esj.2021.v17n8p123

\footnotetext{
Abstract

Ragging is a disruptive behavior mostly observed among senior students of many institutes towards their junior sub-ordinates.

The following study evaluated the perception of newly admitted students about ragging in one of the public medical college of Karachi, Pakistan i.e., Karachi Medical and Dental College. Out of 140 newly admitted students of first year MBBS, 102 participants were enrolled in this study. The data was
} 
collected in two steps, i.e., Questionnaire A was distributed among the students on the orientation day whereas, Questionnaire B was distributed one week after the orientation to the same students who had filled the Questionnaire A. Data was analyzed using Statistical Package for Social Sciences (SPSS) version 20. Majority of participants were aware about ragging. Data of Questionnaire B revealed that about half of participants 52 $(50.9 \%)$ got ragged on the orientation day, while most of the students faced mild to moderate intensity ragging. Males were found to be more frequent victim of ragging as compared to females.

The present study indicates that ragging may have a negative impact on the morale and self-confidence of many students; moreover, the study suggested that serious actions shall be taken against ragging. Formation of an antiragging committee can provide great aid to the newly admitted students on their first day, promoting an anti-ragging environment within the institute and ensuring prevalence of such environment in order to prevent negative impacts of ragging.

Keywords:Ragging, Anti-ragging, Medical students, Newcomers, Harmless tradition

\section{Introduction:}

The term 'ragging' can be defined as a disruptive behavior that involves treating any individual particularly student offensively(Desai, 2009; Nallapu, 2013) either physically or verbally to create a feeling of fright or to intimidate an individual. Hazing, fagging, bapteme (French); doop (Dutch); and mopokaste (Finnish) all are altered words for a similar, old and offensive custom of bullying new students as a rite of passage for them into their first year of professional college or university (Garg, 2009) and as an essential part of an "introduction development" as they call it; (Shareef et al., 2015), the popularity of ragging has its origin from a myth that ragging makes student bold and emotionally strong gives this practice passive social acceptance.

Ragging has been in existence since the Anno Domini (A.D.) era. Starting from the European Universities, this practice spread far and wide throughout the world where seniors would play practical jokes in order to welcome freshmen in their institutes. Later many military organizations throughout the world adopted such rituals of physical jokes (Shinde, 2017: 664-665). In the Indo-Pak subcontinent it was first introduced by the British Military School. At first it was rather in a lighter and milder tone to help students relax and become comfortable in the new environment. However, with a period of time it developed into a much torturous and grievous 
practice which is still practiced in many military and civilian institutes of the Indo-Pak subcontinent (Kaiser, 2008).

It appears that two different schools of thought tend to exist among students related to ragging and its impact. The first school of thought believes ragging to be a harmless and a traditional way to introduce newly admitted students and glorify it as a personality developing practice, whereas, the second group considers ragging as a selfish and deplorable crime committed by senior students which trigger social and emotional problems in new-comers.

Therefore, certain students initiated the development of the anti-ragging team in Karachi Medical and Dental College, but it is still in its primitive form due to the arising conflicts between two groups having different perspectives. The main focus of this study is to find the perspective of newly admitted students, whether they perceived ragging as a healthy way of interaction or as a menacing behavior. This study also aimed to determine the impact of ragging on students and the impact of the anti-ragging team in the prevention of ragging. This study adds significant insights about ragging, its impact and perspective of newcomers. This study also suggests some strategies for authorities of medical institutions which can help them to put a full stop on this traditional practice of ragging. According to the author's knowledge, this is the first study conducted in Pakistan which determines the role of antiragging body in preventing ragging in any educational institute.

\section{Methodology}

A descriptive quantitative study was conducted from Dec'19 to March'20 in one of the known medical institutes of Karachi, that is Karachi Medical and Dental College (KMDC), Pakistan. Target population of study was newly admitted students of first-year MBBS, inclusive of both genders. The study was done with the help of two self-administered, self-structured questionnaires i.e. Questionnaire A (QA) and Questionnaire B (QB) prepared after a focused group discussion with some seniors and the members of the anti-ragging team. Pilot evaluation on a group of 16 students validated both questionnaires. The reliability coefficient, including Cronbach alpha, was found significant.

\section{- Questionnaires}

Questionnaire A (QA) consisted of questions related to general awareness of newly admitted students regarding general information of ragging. Student's perception on ragging was investigated using (0-5) scored Likert style scale consisting of five questions.

Questionnaire B (QB) is used to evaluate the number of students who got ragged on the orientation day (frequency), the intensity of ragging they faced, their ragging experience and the impact of ragging on them. 
QB also evaluated the success of anti-ragging team in the prevention of ragging.

\section{- Data Collection}

Sample size was found to be 135 using Openepi at 95\% confidence interval. A two-stepped sampling technique was designed. In the first stage, Questionnaire A(QA) was rotated among 140 newly admitted students through random sampling method on their orientation day, students were asked to mention their merit number in order to track them later for QB however their names were kept confidential, whereas in the second stage, Questionnaire $\mathbf{B}(\mathbf{Q B})$ was rotated to same participants on their first day of academic year which was around a week after the orientation to compute the feed-back of newly enrolled students after their ragging. Students participated in the study voluntarily. To encourage honest answers students were assured anonymity.

\section{- Data Analysis}

The data was collected and analyzed by using Statistical Package for Social Sciences (SPSS-20). The frequency and percentage were calculated for the quantitative variables. The association of ragging with gender was calculated by using the Fisher exact test, cut-off p-value of $<$ 0.05 was considered as significant.

\section{Results}

Tracking the same participants for QB after a week was quite challenging as some of the participants opted for another medical university while some switched their field from MBBS to BDS. Out of 140, 125 QA were obtained on Orientation day however the data of 102 participants with duly filled questionnaires $\mathrm{A}$ and $\mathrm{B}$ included for final analysis making a response rate of $(72.85 \%)$.

\section{Pre-ragging}

Data of QA revealed that the majority of participants were already aware of ragging through social media $65(63.7 \%)$ and friend/senior $19(18.6 \%)$. About half of total participants 57(55.8\%) were expecting mild, $26(25.4 \%)$ moderate intensity of ragging while very only few $4(3.9 \%)$ were expecting intense ragging $(\mathrm{p}=0.15)$. Both Males 38(37.3\%) and Females $64(62.7 \%)$ participated in the study.

The perspective of participants is tabulated below in Table $\mathbf{1}$ which indicates that the majority responded negatively, disagree $27(26.47 \%)$ and strongly disagree $16(15.3 \%)$ on the statement that ragging is a good source of senior-junior interaction. 
About $9(8.8 \%)$ agreed and $49(48.03 \%)$ strongly agreed on ragging within limitation is fun. Whereas, 33(32.35\%) disagreed and $13(12.74 \%)$ strongly disagree on "ragging help in building self-confidence", 26(25.5\%) and 16(15.3\%) Disagreed and strongly disagreed on statement 'Ragging doesn't have any impact on mental health' respectively. 35(34.3\%) disagree on statement "ragging being a healthy college tradition" while $26(25.5 \%)$ agreed.

\begin{tabular}{|c|c|c|c|c|c|}
\hline \multicolumn{6}{|c|}{$\begin{array}{l}\text { TABLE 1: PRESPECTIVE OF NEWLY ADMITTE } \\
\text { REGARDING RAGGING } \\
\text { In Frequency }(\mathrm{n}) \text { and Percentage }(\%)\end{array}$} \\
\hline \multirow{3}{*}{$\begin{array}{l}\text { Ragging is } \\
\text { a good } \\
\text { source of } \\
\text { senior } \\
\text { junior } \\
\text { interaction } \\
\text { Ragging } \\
\text { within } \\
\text { limitation is } \\
\text { all fun }\end{array}$} & $\begin{array}{l}\text { Strongl } \\
\text { y Agree }\end{array}$ & Agree & Neutral & Disagree & $\begin{array}{l}\text { Strongly } \\
\text { Disagree }\end{array}$ \\
\hline & $\begin{array}{c}5 \\
(4.90 \%)\end{array}$ & $\begin{array}{c}28 \\
(27.45 \%)\end{array}$ & $\begin{array}{c}26 \\
(25.5 \%)\end{array}$ & $\begin{array}{c}27 \\
(26.47 \%)\end{array}$ & $\begin{array}{c}16 \\
(15.32 \%)\end{array}$ \\
\hline & $\begin{array}{c}9 \\
(8.8 \%)\end{array}$ & $\begin{array}{c}49 \\
(48.03 \%)\end{array}$ & $\begin{array}{c}17 \\
(16.66 \%)\end{array}$ & $\begin{array}{c}20 \\
(19.6 \%)\end{array}$ & $\begin{array}{c}7 \\
(6.8 \%)\end{array}$ \\
\hline $\begin{array}{l}\text { Ragging } \\
\text { helps in } \\
\text { building } \\
\text { self } \\
\text { confidence }\end{array}$ & $\begin{array}{c}6 \\
(5.8 \%)\end{array}$ & $\begin{array}{c}24 \\
(23.52 \%)\end{array}$ & $\begin{array}{c}26 \\
(25.5 \%)\end{array}$ & $\begin{array}{c}33 \\
(32.35 \%)\end{array}$ & $\begin{array}{c}13 \\
(12.74 \%)\end{array}$ \\
\hline $\begin{array}{l}\text { Ragging } \\
\text { has no } \\
\text { impact on } \\
\text { mental } \\
\text { health }\end{array}$ & $\begin{array}{c}14 \\
(13.7 \%)\end{array}$ & $\begin{array}{c}18 \\
(17.62 \%)\end{array}$ & $\begin{array}{c}16 \\
(15.32 \%)\end{array}$ & $\begin{array}{c}26 \\
(25.5 \%)\end{array}$ & $\begin{array}{c}16 \\
(15.32 \%)\end{array}$ \\
\hline $\begin{array}{l}\text { Ragging is } \\
\text { a healthy } \\
\text { college } \\
\text { tradition }\end{array}$ & $\begin{array}{c}4 \\
(3.92 \%)\end{array}$ & $\begin{array}{c}26 \\
(25.5 \%)\end{array}$ & $\begin{array}{c}24 \\
(23.52 \%)\end{array}$ & $\begin{array}{c}35 \\
(34.3 \%)\end{array}$ & $\begin{array}{c}13 \\
(12.74 \%)\end{array}$ \\
\hline
\end{tabular}




\section{Post-ragging}

Data from QB revealed about half 52(50.9\%) of participants i.e. 27 $(71 \%)$ males and $25(39 \%)$ females got ragged significant difference of $(\mathrm{p}=$ 0.02 ) revealed a significant association between ragging and gender

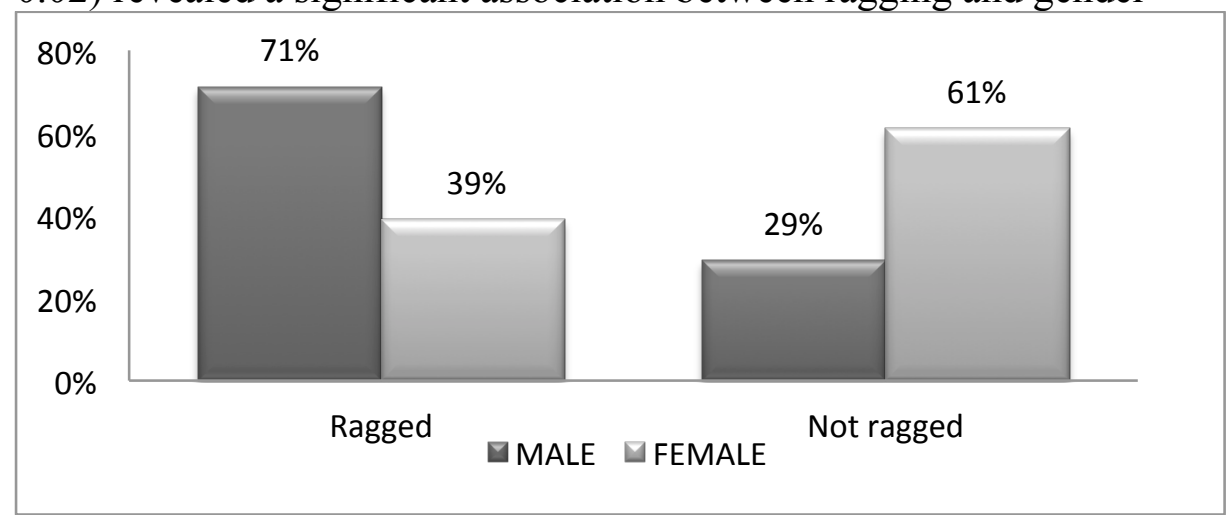

Fig 1: Frequency of ragging among newly admitted students in percentage (\%)

Among 52 participant majority of them faced mild 35(67.3\%) to moderate $16(30.8 \%)$ intensity of ragging. Experience and impact of ragging on those who got ragged is shown Figure 2 and Figure 3 as the most common experience of participants who got ragged was fun $22(42.3 \%$ ) (M: $48.10 \%$; F: $36 \%$ ) while according to $1 / 3$ the experience was humiliating (M: $22.20 \%$; F: $44 \%) p$-value was found to be 0.03 i.e. $(p>0.05)$

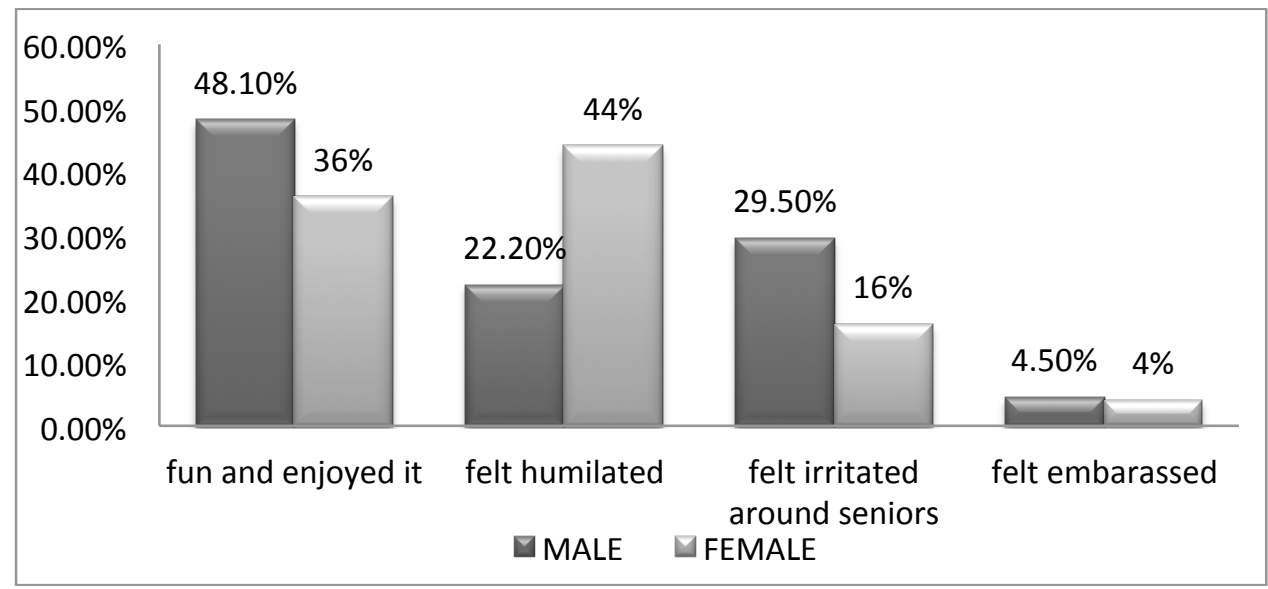

Fig 2: The overall ragging experience in percentage (\%)

Regarding the impact of ragging a significant difference between two gender is found $(\mathrm{p}=.002)$. A great majority of participants i.e. 52 percent females 
and 26 percent males were of the view that there was no impact of ragging on their mental health while the most common response among male participants was shattered self-confidence (M: 37\%; F: 12\%)

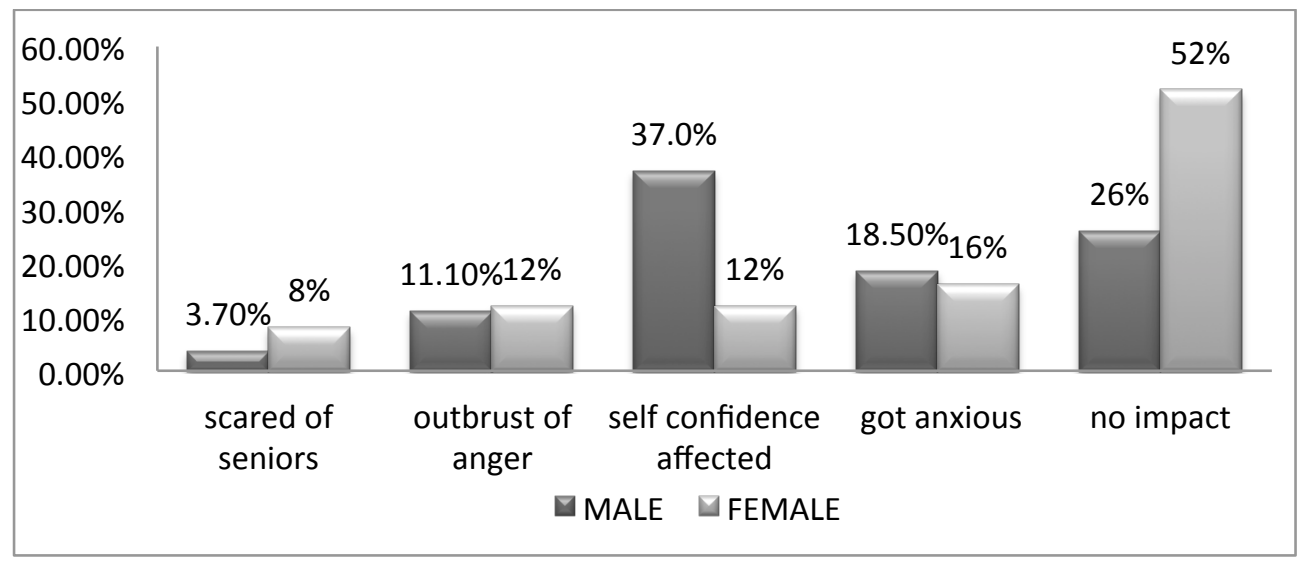

Fig 3: The impact of ragging in percentage (\%)

Out of 102 majority of participants accepted that anti-ragging team was mild $53(52.4 \%)$ to moderate $21(20.6 \%)$ successful in preventing ragging while according to $24(23.5 \%)$ it was not.

\section{Discussion:}

Ragging is considered to be an icebreaker between juniors and seniors on the first day of admission where a certain amount of teasing by seniors is done with the intension to have some fun at the expense of the new students, however, the negative impacts causing emotional, physical, and social problems among victims often seem to be neglected. An exponential increase is observed in many parts of the world specially in the Indo-Pak subcontinent i.e., India, Pakistan, Sri Lanka and Bangladesh. Moreover, this act of ragging is not only limited to educational institutes, hostels and military academies but has now penetrated many other aspects and fields of the society (Wajahat, 2014). Ragging seems to be a rising problem in many universities of Pakistan with many reported cases and is the most fundamental cause of frustration and depression among newly admitted(Gulzar et al., 2012; Wajahat, 2014). Every student is scrutinized on the level of their emotional tolerance and it may sometimes result in mental and physical abuse of the children. A large population in the educational sector suffers from the trauma of ragging which creates a discrepancy in their social and emotional conduct. 
Getting admission in one of the government professional medical institutes of Karachi is indeed a hectic process and requires a great amount of hard work. Students after being through all of this, enter the premises of college with high aspiration, however, ragging turns their memorable day into a nightmare, few minutes of fun for seniors can water the roots of negative emotions including perpetuating fear, low self-esteem, irritability, anger and in severe case one may develop long-term consequences such as depression and institutional phobia (Castaldelli-Maia, 2012; Wajahat, 2014).Also the negative sentiments such as frustration, mortification and brutality of ragging leaves a irremovable dent on student's mental health(Rao, 2015), ragging adds onto the already overflowing list of negatives emotions among freshmen medical students (Shareef et al., 2015), thus the concept of tradition or harmless fun need to be discouraged which can damage the personality of highly ambitious students.

The majority of new-comers participated in this study were females, the female majority can easily be justified by the fact that study was done in a professional medical college of Pakistan (Moazam\&Shekhani, 2018). More than two-thirds of participants already had an idea about ragging which was possible due to an access to social networks, television, and some other means of broadcast which was documented by Miranda Sabu, 2018 as well.

Ragging within some limitations is all fun; this statement was supported by almost three-fourths of the participants. The results of Nallapu, 2013supported the results of this study that ragging is acceptable and fun as concluded by around three-fourth of the participants, Nallapy,2013 in his study asked the same question from senior batches and almost all of them agreed that ragging should not cross certain limits and serious punishments should be given to the students who participate in damaging forms of ragging.

Many previous studies which regarded ragging as a personality enhancing practice or a practice that boosts self-confidence (Gamage, 2017; Nallapu, 2013). Gamage found ragging to be effective on students with the rural or low socioeconomic background as they have a deprived personality on such students mild ragging force them to communicate with people thus enhance their communication skill (2017), however the majority of students admitted in KMDC belong to the urban background and thus the confidenceboosting effects of ragging is not supported by the participants of this study.

Ragging is considered as a masculinity test for boys and males underperforming or being whiny about it are considered to be weak and become a frequent victim of mockery and harassment (Rao et al., 2018); Moreover boys become an easy victim of ragging in medical college where they are easily identified as a newcomer because of their minority whereas the ragging of female students is usually taken seriously among institutes and 
more severe punishments are given to the offender (Marin et al., 2008; Rao et al., 2018)

Males have a strong physical enduranceas compared to females, moreover males have more peer pressure of being accepted as strong and "cool" among their companions thus even those who don't like it pretend that they have enjoyed it (Rao, 2015). Females are considered to be more emotional, sensitive, and outspoken as compared to males (Kring\&Gordan, 1998) hence their description of ragging activity wasn't fun and enjoyment keeping out a fraction of female participants.

Each student has their range of ragging strength, some are more mentally sensitive than others, however, for them only a slight action intended for amusement and laugh can initiate a series of psychological effects resulting in severe hindrance and extreme misery (Nallapu, 2013). Shattering of self-confidence makes students feel incapable, dependent and worthless which in extreme case may result in suicidal ideation (Manani, 2014). Ragging has multiple aspects such as psychological, behavioral, and political ones, so a more integrated study needs to be done to understand the phenomenon.

\section{Strategies to Prevent Ragging Among Medical Institutes:}

To maintain healthy institutional environment, it is a primary responsibility of authority to punish the offenders. Institutional authorities play a major role in prevention of ragging. The following methods and techniques are suggested which can help authorities in prevention of ragging among medical institutes.

1. Zero-Tolerance for Ragging: Before the commencement of new academic session or before the orientation ceremony, the dean or principal of medical institution should give a clear warning about zero tolerance for ragging and punishment for offenders stating that ragging in no manner will be acceptable.

2. Formation of Anti-Ragging committee: The menace of ragging can be curbed by forming Anti-Ragging committee in medical institutes consisting senior students, faculty member and staff. These antiragging bodies can play a major role ineffective discouragement of ragging among an institute (Kaiser, 2008)

3. Supervision of Medical hostels: Medical Hostels are one of the common places for ragging and usually ragging in hostels remains unreported or unnoticed. Thus, to prevent ragging in hostel a strict supervision of Hostels is needed. It can be done through installed 
CCTV cameras at strategic points. Moreover, supervising members should keep an eagle eye on the activities of hostel students.

4. Alternative for Senior-Junior interaction: The principal purpose of ragging is to provide a mechanism of interaction and socialization (Shakya\&Maskey, 2012). However, an alternate is required of ragging in order to promote a healthier manner of socialization which is free of cruel ragging customs and much more effective which can be done by the help of psychological sciences. Many alternatives can be used such as pre-session parties for the fresher, social gathering of juniors and seniors in the presence of authorities, interactive games, community work, trips etc. in which seniors and juniors are bound to work and participate together. Socialization in a friendly way in the form of interactive games and activities can nullify the harmful impact which was produced by ragging.

5. Awareness through media: Social media and television media shall talk about the grievous impacts of ragging and about the information regarding Anti-Ragging committees and material. Moreover, the students need to be educated about the negative impacts of ragging by pamphlets and interactive sessions. This material can also be emphasized in the prospectus of institution, admission advertisements and admission forms. Severe penalty towards Ragging or RaggingFree placards or notices depicting the consequences of such an act needs to be displayed at strategic points of the premises.

6. Workshop or Sessions for awareness of Ragging hazards: Creating awareness amongst students, management and faculty of institute about the ill-effects of ragging can play a crucial role in mitigating the bane of ragging in the colleges (Gorea et al., 2012).

7. Seniors Counseling: Proper counseling of senior students through sessions and spreading awareness among them about the after-effects of ragging should be done.

\section{Limitation and Future Direction:}

This study consisted new-admitted students of M.B.B.S. This survey did not include items regarding perception of seniors or anti-ragging team. Future research can explore the perception of seniors or anti ragging team regarding ragging and its impact. Study was done in a single medical college of Karachi; Pakistan thus different results can be expected from other medical colleges. It could be interesting to follow up the study in different contexts. This study doesn't use any measuring scale to examine the negative 
emotions among newcomer such as stress, anxiety and depression. In future more integrated study is needed on multiple aspects of ragging such as psychological, behavioral, and political ones. Moreover, the future researches are expected to add insights about the role of anti-ragging team and prevention measures in controlling ragging among medical institutes.

\section{Conclusion:}

The following article present a detailed account of discussion on the perspective of newly admitted students of Karachi Medical and Dental College on ragging followed by its impact on students who faced ragging. Another aimed topic discussed in this article is the impact of the anti-ragging team in prevention of ragging and ensuring the safety of students and their self-confidence. Ragging is contemplated as an act of humiliation and misconduct towards newly admitted students. Titled under different names and forms, it has harmed a large population of students mentally and physically. With its roots still planted in institutes all over the world and its stems being watered well by generation after generation it has never failed to harm its target. While it still exists in most of the institutes, some are stepping up against the bully and putting an end to ragging by forming an anti-ragging committee.

To end the taboo of ragging, institutes have to be responsible to put a stop on it by forming anti-ragging counsel, to resolve matters of ragging and by creating anti-ragging teams to patrol the premises of institute during the commencing days of newly admitted students in order to avoid any mishaps. A system should be established to govern the atypical behaviors of those who contribute to severe ragging. Activities other than ragging to conclude supremacy among students should be introduced.

\section{Acknowledement:}

The author wants to thank all the newly admitted students of Karachi Medical and Dental College who participated, member of anti-ragging team and the principal of Karachi medical and dental college for allowing us to conduct the study.

\section{References:}

1. Castaldelli-Maia, J. M., Martins, S. S., Bhugra, D., Machado, M. P., De Andrade, A. G., Alexandrino-Silva, C., ...\&Alves, T. C. D. T. F. (2012). Does ragging play a role in medical student depressioncause or effect?. Journal of Affective Disorders, 139(3), 291-297. https://doi.org/10.1016/j.jad.2012.02.003

2. Desai, C. (2009). Ragging: Let's say NO to it. Indian journal of $s$ pharmacology, 41(2), 59. https://doi.org/10.4103/0253-7613.51338 
3. Gamage, S. (2017). "PSYCHOLOGICAL, SOCIOLOGICAL, AND POLITICAL DIMENSIONS OF RAGGING IN SRI LANKAN UNIVERSITIES. Social Affairs: A Journal for the Social Sciences, 1(7), 13-21.

4. Garg, R. (2009). Ragging: a public health problem in India. Indian journal of medical sciences, 63(6), 263-271. https://doi.org/10.4103/0019-5359-53401

5. Gorea, R. K., Nagar, B., \& Arora, P. I. A. (2012). Individual, community and institutional responsibility in prevention of ragging ofstudents in educational institutions. Sciences Journal, 2(2), 53-59.

6. Gulzar, S., Yahya, F., Nauman, M., Mir, Z., \&Mujahid, S. H. (2012). Frustration among university students in Pakistan. International Research Journal of Social Sciences, 1(4), 7-15.

7. Kaiser, F. (2008). Ragging in Medical Colleges. Rawal Medical Journal, 33(1), 107-108.

8. Kring, A. M., \& Gordon, A. H. (1998). Sex differences in emotion: expression, experience, and physiology. Journal of personality and social psychology, 74(3), 686.https:// doi.org/10.1037/00223514.74.3.686

9. Manani, P. (2014). Peer pressure and ragging as the determinants of suicidal ideation among the students of professional and nonprofessional courses (Doctoral dissertation, Dayalbagh Educational Institute).

10. Miranda Sabu , A. J., Jisty benny , LintaLalan , Manoj PS , PrecillaD'Silva (2018). "A Study to Assess Knowledge about Hazards of Ragging among Undergraduate Nursing Students in a Selected College at Mangaluru." International Journal of Health Sciences and Research 8(10), 172-177.

11. Moazam, F., \&Shekhani, S. (2018). Why women go to medical college but fail to practise medicine: perspectives from the Islamic Republic of Pakistan. Medical Education, 52(7), 705-715. https://doi.org/10.1111/medu.13545

12. Nallapu, S. S. (2013). Students perceptions and feedback on ragging in a south indian medical college. South East Asian Journal of Medical Education, 7(2), 3.

13. Rao, M., et al. (2018). "A Study on the Prevalence and Nature of Ragging Practices in Selected Educational Institutions in India." Contemporary Education Dialogue 15(2), 187-202. https://doi.org/10.1177\%2F0973184918781213

14. Rao, M., Sonpar, S., Sen, A., Seshadri, S. P., Agarwal, H., \&Padalia, D. (2015). Psychosocial Study of Ragging in Selected Educational Institutions in India. New Delhi, India: Jawaharlalnehru University. 
15. Shakya, D. R., \&Maskey, R. (2012). 'Ragging': What the medical students of a health institute from Eastern Nepal say?. Sunsari Technical College Journal, 1(1), 27-32. https://doi.org/10.3126/stcj.v1i1.8658

16. Shareef, M. A., Alamodi, A. A., Abu-Dawas, R. B., \&Anwer, L. A. (2015). Losing lives to the peril of ragging. International journal of adolescent medicine and health, 27(1), 105-105. https://doi.org/10.1515/ijamh-2014-0015

17. Shinde, V. G., (2017), The Menace of Ragging in Educational Institutes: A Human Right Perspective, International Journal of Advanced Research and Development. Available at: www.advancedjournal.com

18. Wajahat, A. (2014). "Harassment due to ragging." Procedia-Social and Behavioral Sciences 113, 129-133. https://doi.org/10.1016/j.sbspro.2014.01.019 